\title{
Certainty and Uncertainty: The "Point, Line and Surface" of Parc de La Villette in Paris
}

\author{
Quan'an Chen ${ }^{1, *}$ Junbo $\mathrm{Li}^{2}$ \\ ${ }^{1}$ School of Architecture, Zhengzhou University, Zhengzhou, Henan, China \\ ${ }^{2}$ The University of Sydney, Sydney, Australia \\ *Corresponding author.Email: 394014745@qq.com

\begin{abstract}
Parc de La Villette in Paris is the work of deconstructivist design master Tschumi. The designer arranges, intersects, and overlaps three very different systems of point, line, and surface, presenting various unexpected effects, embodying the uncertainty of "accidental", "coincidental", "inconsistent", and "discontinuous" "deconstruction", as well as an inherent and definite logic at the same time.
\end{abstract}

Keywords: point, line, surface, deconstructivism

\section{INTRODUCTION}

Parc de La Villette is one of the nine major projects built in Paris to commemorate the 200th anniversary of the French Revolution. The park is located in the northeast corner of Paris and covers an area of about 55 hectares. The Ourcq Canal divides the park into two parts: the north and the south. The north area displays the vision of technology and the future, and the south area takes the artistic atmosphere as the theme.

As early as the beginning of the construction of the park, the construction goal was set as: a park that belongs to the 21 st century, full of charm, unique and of profound ideological significance. It must not only meet people's physical and spiritual needs, but also be an open green space that combines sports, entertainment, natural ecology, science, culture, and art. In addition, the park must become a place for tourists from all over the world to communicate.

It is well known that point, line, and surface are the basic elements of plane composition, and the principle of their composition is to creatively combine these basic elements according to the law of formal beauty. The point, line, and surface in landscape design are the materialization of abstract point, line, and surface in the plane composition, replacing them with specific elements of landscape design, and giving them a certain size, shape, material, etc. The most impressive thing about the design of Parc de La Villette is the designer's profound and skillful use of point, line and surface elements and his profound grasp of deconstructionism.

\section{THE "POINT, LINE AND SURFACE" IN THE DESIGN OF PARC DE La VILLETTE IN PARIS}

\section{A. Point}

In landscape design, a point can indicate a location and has a certain shape, size and material. Objects of any shape can be understood as points in a specific environment. A point is easy to attract people's attention and becomes a visual center, enriching the shape and breaking the monotony. In landscape design, many landscape elements can be used as points to enrich the landscape level, such as ornamental plants, stones, sculptures, seats, street lamps, road signs, fountains, etc.

The gathering and dispersing changes of different shape points will make people have different visual feelings, gathering and dispersing actively, and associating activity and inertia, which can form a landscape effect with rich and varied spatial levels. The regular arrangement of points presents a beautiful order, and the irregular repetition and change of points will also make irregular shapes and spaces produce a sense of rhythm of movement. When the number and location of points change back and forth in space, the visual effects are quite different.

In the design of Parc de La Villette, the point system refers to the red structures neatly arranged in a grid system of $120 \mathrm{mX} 120 \mathrm{~m}$ - "folies". The "folies" that exist as points seem to be arranged regularly, but when they are combined with original spaces, buildings, and rivers, they produce unexpected artistic effects. Some fall into the green space, which are particularly eye-catching on the large area of grass and the platanus trees; some are accompanied by the old buildings and are organically combined with the beige 
architectural stone walls; some have become an organic whole as a pedestrian bridge across the river. The point system establishes an invisible order in the seemingly uncentered park, thus achieving the effect of being accidental, random and unified.

\section{B. Line}

A line is the movement of a point in one direction, which is usually embodied in different forms of paths in landscape design - they can not only serve as a traffic guide for tourists, but also serve as the structural context of the landscape ("Fig. 1"). Of course, lines in landscape design can also define boundaries, such as the outline of landscape elements, the skyline of the landscape or the boundary line of different quality surfaces; or the pattern lines on the material, such as the pattern of the scenery wall, etc.

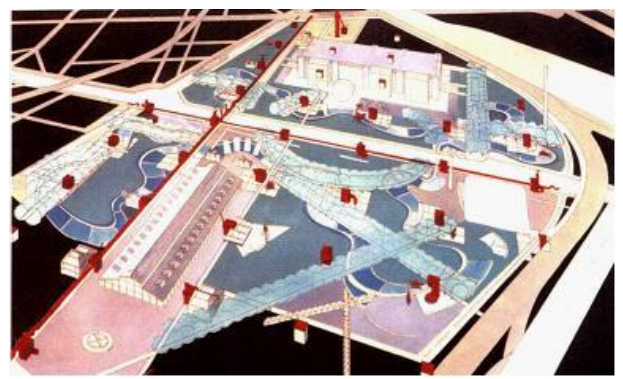

Fig. 1. Point, line and surface system of Parc de La Villette 1.

a. Image source: Bernard Tschumi's Works and Thoughts, China Electric Power Press 2006

In the design of Parc de La Villette, the line system consists of straight lines and curves. The two straight lines intersect perpendicularly in the park, one is the original water canal that runs from east to west in the site, and the other is a newly designed 5-meter-wide elevated corridor running north-south, which lies on the west side of the site. The curves refer to the walking trails in the park, which seem to be aimless paths that run through the entire park and connect various scenic spots in the park. During the wandering, almost all the characteristic landscapes and recreational activities of the park are covered.

The combination of straight lines and curves in the park is also quite original. The elevated corridor that runs from north to south breaks the monotony of the original east-west canals in the base. The wavy-shaped corridor connects the science and technology industrial hall, and the music city and the multifunctional hall, becoming a powerful compositional element in the park. The free curves are soothing and soft, alleviating the rigidity brought about by the two straight lines. The combination of curve and straight, rigid and soft, makes the park's composition reach an invisible equilibrium in the seemingly accidental contrast.

\section{Surface}

A surface is the movement track or collection of points and lines, and it is the most widely used modeling element in modern landscape design. It can be divided into two types: regular surface and irregular surface. Regular surface includes round surfaces, triangular surfaces, square surfaces, and multideformation surfaces. Irregular surface is a combination of free curves and straight lines, which is more flexible and random than geometric surfaces. ("Fig. 2")

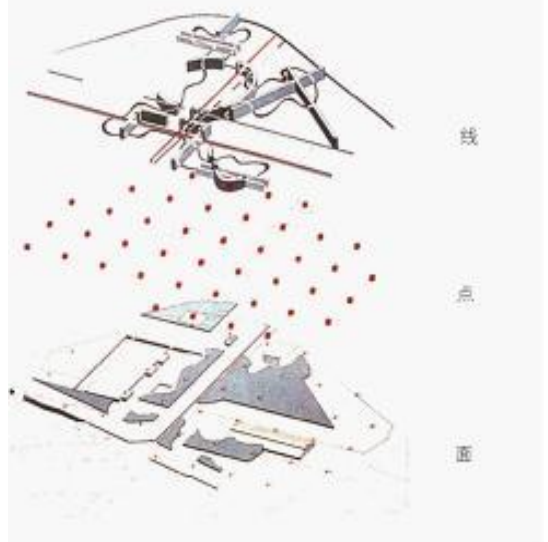

Fig. 2. Point, line and surface system of Parc de La Villette 2.

a. Image source: Bernard Tschumi's Works and Thoughts, China Electric Powe Press 2006

In the design of Parc de La Villette, the content and form of the surface are very rich, the space of various shapes, the paving of various materials, and even the ten themed gardens in the garden - mirror garden, wind garden, water garden, grape garden, bamboo gardens, sound round halls, horror fairy tale gardens, youth garden, and dragon garden, which can all be regarded as manifestations of the surface.

These different shapes meet the needs of tourists of different cultural levels and ages. The "Mirror Garden" consists of 20 monolithic stone monuments erected in the woods, with mirrors on one side, and the scenery inside and outside the mirrors contrasts each other, making it difficult to distinguish between true and false; The play facilities in the "Wind Garden" allow children to experience subtle movement; The misted landscape of the water in the "Water Garden" and the computercontrolled water curtain, falling water or dripping water landscape are carefully arranged, which is full of ornamental nature. In summer, it is a small swimming pool that children love; The "Grape Garden" artistically reproduces the vineyard landscape in the Bordeaux region of southern France; the sunken "Bamboo Garden" bamboo forest landscape is a rare "exotic" for the citizens of Paris; "Youth Garden" is composed of a series of very sculptural and visualized game facilities, and the "single-plank bridge" makes the teenagers feel like walking a tightrope. 


\section{DECONSTRUCTIVE FEATURES OF POINT, LINE AND SURFACE IN PARC DE LA VILLETTE IN PARIS}

The points in Parc de La Villette - "folies" have an average volume of about 10 cubic meters. The actual size varies with different functions. Most "folies" exist
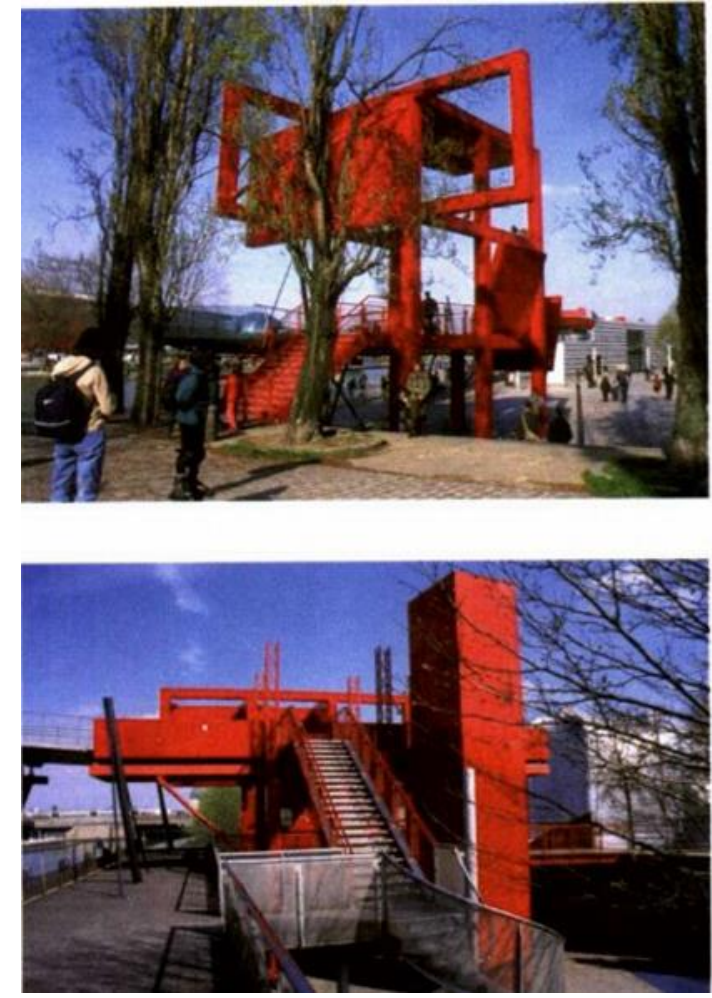

Fig. 3. Red points - "folies".

Although these points are arranged regularly, when combined with different places and buildings, they produce unexpected taste. They are not only definite symbols and visual tone, but also produce accidental combination effects.

The various lines and surfaces in the park have the same characteristics. Straight lines - drains and elevated corridors, their vertical intersection clearly define the space composition of the park; as curved park paths, they run through the entire park irregularly, connecting various scenic spots and enlivening the spatial form. They have both traffic guidance functions and are landscape elements. Their combination has the instability of deconstructivism - "accidental" and "random". The surfaces that they divide, the ten theme gardens, also show irregular shapes, but they are given different landscape textures and actual functions according to local conditions.

In short, the point, line, and surface of Parc de La Villette have a certain degree of contingency and only as high-tech sculptures, but some "folies" have been given actual functions, such as information centers, eateries, coffee bars, handicraft rooms, infirmaries, and so on. The red points become a kind of strong and easily recognizable symbol, which are not only the visual tone of the park, but also coordinate points that can mark the location. ("Fig. 3")
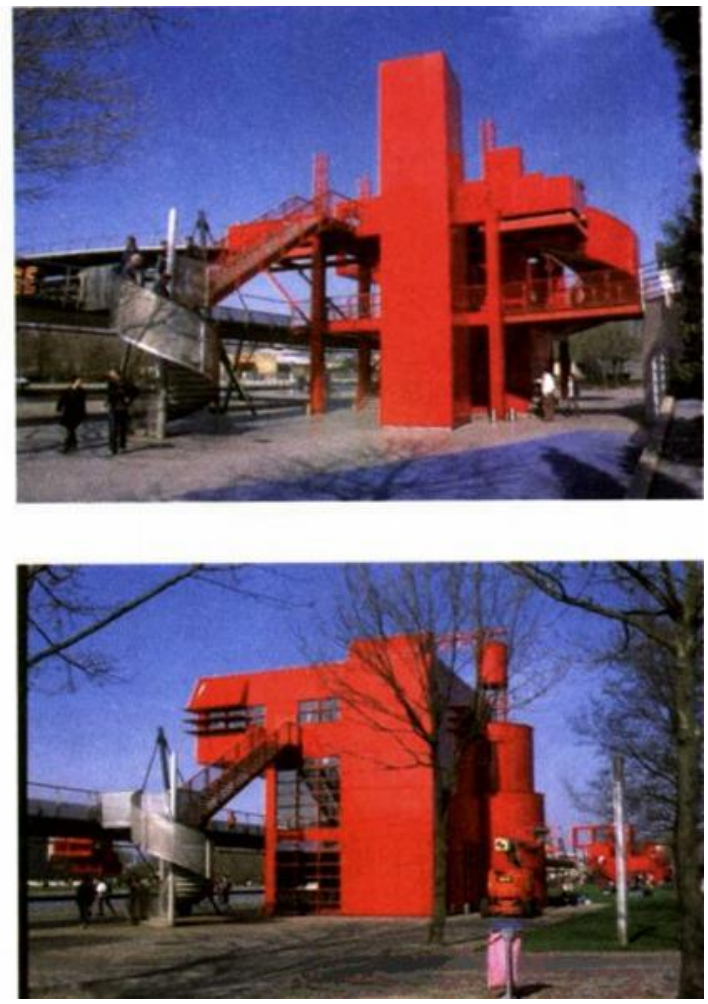

Image source: Bernard Tschumi's Works and Thoughts, China Electric Power Press 2006 randomness, and at the same time there is a certain internal logic, which is a contradictory unity of certainty and uncertainty.

\section{CONCLUSION}

Each system of point, line, and surface in Parc de La Villette in Paris is independent. When three independent systems are randomly superimposed and interact with each other, there will be various uncertain effects - unexpected, conflicted and opposite, which is the embodiment of deconstructive design thinking. At the same time, the three systems are complete and orderly, and their combination implies a stable and definite logic.

\section{References}

[1] Edited by the Editorial Department of the Master Series. Bernard Tschumi's Works and Thoughts [M]. China Electric Power Press, 2006. (in Chinese) 
[2] Wassily Kandinsky, translated by Luo Shiping, Wei Dahai, Xin Li. Wassily Kandinsky: Point and Line to Plane [M]. Beijing: Renmin University of China Press, 2003. (in Chinese)

[3] Zeng Yingying. Discussion on the Application of Plane Constitution in Modern Landscape Design [D]. Nanjing: Nanjing Forestry University, 2008. (in Chinese)

[4] Zheng Yongli. The Formation of Plane Applying in Landscape Architucture [D]. Harbin: Northeast Forestry University, 2005. (in Chinese)

[5] Zhu Jianning. Fashion and Innovation, Enlightenment from La Villette Park in Paris [J]. Garden, 2011(12). (in Chinese)

[6] Zhang Yingxing. A Joyful Tour and Artistic Rest at the Green Reception Hall in Paris - Analysis of La Villette Park, France [J]. Garden, 2005(2). (in Chinese)

[7] Tu Shan. La Villette's Environmental Design [J]. Art \& Design, 1998 (10). (in Chinese) 